\title{
PENINGKATAN KOMPETENSI GURU SEKOLAH DASAR MELALUI LESSON STUDY \\ (Sosialisasi LS bagi Guru SD N 1,2 Gentan Baki-Sukoharjo)
}

\author{
Slamet Hw, Tjipto Subadi, Sutama, dan Rita P. Khotimah \\ Jurusan Pendidikan Matematika - FKIP \\ Universitas Muhammadiyah Surakarta
}

\begin{abstract}
Mathematics such as the assumption most people as a difficult lesson. This assumption is not entirely wrong because the average NEM value of elementary and middle school math is almost always located below the average value of the other lessons. The abstract nature of mathematics became the main obstacle to learning, especially for students who are still in the development of concrete or semi-concrete thinking. The situation is exacerbated by the use of methods which are still focused on the teacher (teacher center), not focused on students (child center) so that less activate students. Such conditions often found in schools both public and private. A reality that even when this has been attempted to improve the professionalism of teachers through workshops or upgrading, but the results can not be perceived by the public. Lesson study that is currently being developed in many universities believed to be able to increase the professionalism of teachers. Socialization and simulation results Leson Study conducted on January 13, 2010 against Elementary School teachers Gentan by the Development Team of Realistic Mathematic Education (RME) and Lesson StudyUMS concluded that: (1) The teachers were very enthusiastic and active during the socialization and stimulation, (2) The teachers want to know more about the RME and Lesson Study, (3) is hoping for a follow up such training so that teachers can implement lesson study in class, and (4) most teachers believe: by applying the approach RME through Lesson Study will help improve students' understanding of math that the edges will help improve academic achievement.
\end{abstract}

Kata Kunci: profesionalisme, lesson study, PMRI

\section{PENDAHULUAN}

\section{Analisis Situasi}

Masalah utama pendidikan di Indonesia adalah rendahnya prestasi yang dicapai dan kurangnya minat siswa untuk belajar. Masalah rendahnya prestasi dapat ditinjau dari hasil UAN/UAS tiap tahun. Sedangkan masalah kurangnya minat belajar terutama untuk bidang tertentu, misal matematika karena sebagian besar murid menganggap matematika itu sulit, abstrak dan kebanyakan cara penyajianyapun kurang menarik.

Pemerintah sudah melakukan berbagai usaha untuk memperbaiki mutu pendidikan 
berupa perubahan kurikulum, penataranpenataran, pengadaan buku ajar, penambahan sarana pendidikan dan sebagainya, tapi ternyata belum mampu meningkatkan motivasi siswa untuk belajar sehingga prestasinya menjadi lebih baik.

Sebenarnya inovasi pembelajaran telah banyak dilakukan terutama di perguruan tinggi, tapi imbasnya belum banyak dirasakan di sekolah-sekolah. Keberhasilan pendidikan bukan karena suatu hal yang secara kebetulan, melainkan karena usaha yang terprogram dengan seksama. Guru sebagai ujung tombak di lapangan mempunyai peranan yang sangat menentukan dalam peningkatan mutu. Guru bertanggung jawab untuk mengatur, mengarahkan, dan menciptakan suasana yang mendorong siswa gemar belajar. Guna menunjang tugas guru yang berat ini, perlu adanya kerja sama terus menerus antara dosen LPTK dengan mitra (guru SD di daerah marginal) dalam mengatasi masalah yang sering muncul dalam pembelajaran. Sampai saat ini sebagian besar guru mengajar dengan cara yang konvensional. Peran guru sangat mendominasi kelas dan cara penyampaiannya cenderung satu arah sehingga kurang ada interaksi antara guru dan murid.

Guru SDN 1,2 Gentan sebagai mitra Jurusan Matematika FKIP-UMS, dikatakan sebagai guru SD di daerah marginal yang sering mengalami kesulitan dalam pembelajaran (terutama matematika), akar masalahnya dapat diidentifikasi sebagai berikut:

a. Secara geografis, desa Gentan dimana mitra berada termasuk Sukoharjo yang berbatasan dengan Kota Surakarta. Karena dekat dengan wilayah Surakarta maka untuk berbagai keperluan lebih memilih ke kota Surakarta daripada ke Sukoharjo kota. Sebaliknya keberadaan SDN 1, 2 Gentan yang berada di daerah pinggiran merasa kurang memiliki kedekatan hubungan institusional dengan kantor Dinas tingkat Kabupaten. Guruguru merasa kurang diperhatikan, kurang diberi kesempatan untuk mengikuti kegiatan demi meningkatkan profesionalisme seperti penataran latihan dan workshop, penyegaran, kunjungan kerja, atau kegiatan ilmiah lain sehingga mereka merasa ter-anak tirikan. Akibatnya guruguru kurang innovative, statis, konvensional.

b. Bila ditinjau dari senioritas guru-gurunya, sebenarnya sebagian besar guru SDN 1,2 Gentan dapat dikatakan cukup. Namun dapat disebutkan bahwa belum banyak guru dari SDN 1,2 dalam periode Sertifikasi Guru dalam Jabatan tahun 2006-2009 yang berkesempatan untuk diikut sertakan.

c. Ditinjau dari sarana dan prasarana penunjang pembelajaran, ternyata SDN 1 dan 2 masih kurang memadai. Terutama SDN 2 sebagai SD Inpres tahun 1980, masih sangat kurang dalam banyak hal seperti jumlah dan kualitas ruang yang tidak memadai, peralatan pembelajaran yang tidak lengkap bahkan tidak punya perpustakaan, laboratorium alat peraga dan alat Bantu pembelajaran seperti OHP, computer apalagi jaringan internet.

d. Desa Gentan adalah wilayah pemukiman baru yang berkembang dengan sangat pesat. Pertumbuhan kompleks-kompleks perumahan baru yang pesat menjadikan struktur masyarakat Gentan berubah dari para petani dan buruh bangunan kedalam sebagian besar pegawai dan karyawan kantor. Sekolah-sekolah di Gentan belum menjadi pilihan bagi mereka. Para orang tua lebih senang menyekolahkan anaknya ke kota Surakarta. Ini berarti keberadaan sekolah lokal, walaupun berstatus negeri masih dipandang dengan sebelah mata dan kurang diperhitungkan. Pantas bila siswa-siswanya berasal dari para orang tua penduduk dari kalangan masyarakat 
ekonomi lemah, dan jumlah siswa pun tidak banyak (Tabel-1).

e. Eksistensi mitra (SDN 1,2 Gentan) sebenarnya cukup potensial untuk dapat dikembangkan, minimal setaraf dengan sekolah-sekolah (SDN) di wilayah Surakarta mengingat berada ditengah masyarakat dengan stuktur social ekonomi tingkat menengah kecuali penduduk asli. Bila dikelola dengan baik maka dampaknya terhadap lingkungan sangat positif karena: (1) masyarakat tidak perlu menyekolahkan anaknya ke Surakarta yang akan banyak memberikan efisiensi, (2) lewat Komite Sekolah, masyarakat bisa lebih diberdayakan untuk ikut memajukan sekolah, (3) sekolah yang maju merupakan daya tarik dari berbagai fihak untuk melakukan berbagai aktifitas, membuka lapangan kerja yang dapat meningkatkan kesejahteraan, (4) sekolah yang maju akan membawa kepada lingkungan masyarakat yang sehat, mengurangi tindak kriminalitas, membawa kepada situasi yang kondusif, mapan, tenteram dan membawa kepada masyarakat yang berkarakter dan cerdas.
Tabel Profil Mitra:

SDN 1,2 Gentan, Baki - Sukharjo

\begin{tabular}{|c|c|c|c|c|c|}
\hline \multicolumn{4}{|c|}{ SDN - 1} & \multirow{2}{*}{\multicolumn{2}{|c|}{$\begin{array}{c}\text { SDN - } 2 \\
\text { Guru } \\
\end{array}$}} \\
\hline 1 & \multicolumn{3}{|c|}{ Guru } & & \\
\hline & a. Jumlah & \multicolumn{2}{|c|}{11 orang } & \multicolumn{2}{|c|}{10 orang } \\
\hline & \multirow{5}{*}{$\begin{array}{l}\text { b. Pangkat / Gol } \\
\text { / Status }\end{array}$} & IV.a & 5 & \multicolumn{2}{|l|}{6} \\
\hline & & III.d & 2 & \multicolumn{2}{|l|}{-} \\
\hline & & II.b & - & \multicolumn{2}{|l|}{1} \\
\hline & & II.a & 1 & \multicolumn{2}{|l|}{1} \\
\hline & & WB & 3 & \multicolumn{2}{|l|}{2} \\
\hline & \multirow[t]{3}{*}{ c. Pendidikan } & S1 & 9 & \multicolumn{2}{|l|}{4} \\
\hline & & D2 & 1 & \multicolumn{2}{|l|}{5} \\
\hline & & SMK & 1 & \multicolumn{2}{|l|}{1} \\
\hline & \multirow[t]{4}{*}{ d. Masa Kerja } & $>30$ th & 1 & \multicolumn{2}{|l|}{1} \\
\hline & & $20-30$ th & 6 & \multicolumn{2}{|l|}{5} \\
\hline & & $10-20$ th & 1 & \multicolumn{2}{|l|}{1} \\
\hline & & $<10$ th & 3 & \multicolumn{2}{|l|}{3} \\
\hline & $\begin{array}{l}\text { e. Lls Sertifikasi } \\
\text { Guru }\end{array}$ & \multicolumn{2}{|l|}{ - } & \multicolumn{2}{|l|}{1} \\
\hline 2 & \multicolumn{3}{|c|}{ Siswa } & \multicolumn{2}{|l|}{ Siswa } \\
\hline & a. Jumlah & \multicolumn{2}{|c|}{236 anak } & \multicolumn{2}{|c|}{109 anak } \\
\hline & b. Jumlah kelas & \multicolumn{2}{|c|}{$\begin{array}{l}\quad 7 \text { klas } \\
\text { Klas I }=51(2 \mathrm{kls}) \\
\text { Klas II }=37 \\
\text { Klas III }=36 \\
\text { Klas IV }=41 \\
\text { Klas V }=37 \\
\text { Klas VI }=34\end{array}$} & \multicolumn{2}{|c|}{$\begin{array}{l}\quad 6 \text { klas } \\
\text { Klas I }=19 \\
\text { Klas II }=14 \\
\text { Klas III }=14 \\
\text { Klas IV }=24 \\
\text { Klas V }=20 \\
\text { Klas VI }=18\end{array}$} \\
\hline & \multicolumn{5}{|l|}{$\begin{array}{l}\text { c.Kellsn UASBN } \\
\left(\text { Rata }^{2}\right)\end{array}$} \\
\hline & 1).Th. $2007 / 2008$ & $\begin{array}{l}\text { Bhs.Indo } \\
\text { Matematika } \\
\text { IPA }\end{array}$ & $\begin{array}{l}7,23 \\
6,31 \\
6,94 \\
\end{array}$ & $\begin{array}{l}\text { Bhs.Indo } \\
\text { Matematika } \\
\text { IPA }\end{array}$ & $\begin{array}{l}7.64 \\
5,14 \\
7,14 \\
\end{array}$ \\
\hline & 2).Th. 2006/2007 & $\begin{array}{l}\text { Bhs.Indo } \\
\text { Matematika } \\
\text { IPA }\end{array}$ & $\begin{array}{l}7,65 \\
5,96 \\
7,21 \\
\end{array}$ & $\begin{array}{l}\text { Bhs.Indo } \\
\text { Matematika } \\
\text { IPA }\end{array}$ & $\begin{array}{l}7,24 \\
6,01 \\
6,97 \\
\end{array}$ \\
\hline & 3).Th. 2005/2006 & $\begin{array}{l}\text { Bhs.Indo } \\
\text { Matematika } \\
\text { IPA }\end{array}$ & $\begin{array}{l}7,73 \\
6,24 \\
7,06\end{array}$ & $\begin{array}{l}\text { Bhs.Indo } \\
\text { Matematika } \\
\text { IPA }\end{array}$ & $\begin{array}{l}7,57 \\
5,73 \\
7,18\end{array}$ \\
\hline
\end{tabular}

Sumber: Dokumen Sekolah, 2008.

\section{Perumusan Masalah}

Memperhatikan analisis situasi dn berdasar hasil observasi pendahuluan di sekolah mitra, dapat diidentifikasi berbagai permasalahan pengajaran sebagai berikut:

a. Kondisi pembelajaran di SD N Gentan Baki Sukoharjo memiliki keragaman permasalahan yang dihadapi. Untuk mengantisipasi keadaan sekarang dan 
yang akan datang kiranya permasalahan yang paling krusial dan perlu segera dicarikan solusinya adalah peningkatan aktifitas siswa untuk mau belajar. Oleh karena itu perlu diselenggarakan pengembangan model pembelajaran dengan perencanaan yang mantab dan pelaksanaan yang efektif serta efisien.

b. Guru matematika tingkat pendidikan dasar (SD,SMP) memegang peranan penting dan sekaligus sebagai ujung tombak keberhasilan pendidikan pada jenjang yang lebih tiggi. Oleh sebab itu inovasi-inovasi di bidang pembelajaran yang telah dikembangkan oleh para ahli di berbagai Perguruan Tinggi mutlak harus diikuti agar tidak ketinggalan jaman. Padahal inovasi dimaksud belum terjamah oleh guruguru SD, khususnya di Kecamatan baki Sukoharjo

c. Diakui bahwa antara dosen-dosen LPTK dengan guru-guru sekolah memiliki jarak dikarenakan kurangnya komunikasi, oleh sebab itu perlu dicarikan jalan keluar demi tercapainya komunikasi timbal balik lewat kerja kolaboratif. Adanya komunikasi timbal balik atara guru dengan tim dosen dapat membahas isu-isu kendala yang terjadi pada pembelajaran yang telah dilakukan, kemudian mengembangkan kesepakatan-kesepakatan tentang fokus dan harapan akademik terhadap program pembelajaran di kelas berikutnya. Rutinitas komunikasi antara dosen dan mitra guru matematika akan menemukan kondisi obyektif pembelajaran, baik kelebihan dan kelemahannya. Inisiatif yang tumbuh dari para guru-guru dan didukung kerjasama dengan dosen diharapkan mampu meningkatkan mutu proses dan hasil belajar siswa.
Sampai saat ini tim kolaborasi sebagaimana dimaksud belum pernah terjadi.

d. Beberapa hal yang diyakini sebagai pegangan kerja kolaborasi antara dosen dan guru yaitu bahwa: (1) siswa dalam mempelajari materi pelajaran memerlukan pelayanan, dan bentuk pelayanan itu dapat dipikirkan bersama antara dosen dan guru mitra, (2) disadari bahwa antara dosen dan guru di daerah terdapat jarak, tapi hal ini dapat diatasi dengan kerja kolaborasi dalam berbagai kegiatan secara berkesinambungan, dan (3) kerja terprogram, termonitor dan umpan balik menjadi faktor penentu keberhasilan pembelajaran matematika.

Atas dasar uraian diatas, permasalahan umum yang akan dicari jawabannya melalui kegiatan ini adalah “ bagaimana meningkatkan kemampuan mengajar guru-guru SD lewat kerja kolaborasi dengan tim dosen LPTK khususnya tim dosen matematika FKIP-UMS”.

Secara lebih spesifik, permasalahan ini dapat dirinci menjadi pertanyaan sebagai berikut:

a. Bagaimana proses peningkatan kemampuan mengajar guru matematika kaitannya inovasi pembelajaran lewat pendekatan Lesson Study?

b. Bagaimana cara peningkatan motivasi siswa untuk belajar matematika lewat kerja kolaborasi dengan tim dosen LPTk secara berkesinambungan?

c. Adakah peningkatan pemahaman konsep siswa setelah dilakukan pembelajaran dengan pendekatan Lesson Study?

\section{Tinjauan Pustaka}

Lesson Study pertama kali dikembangkan oleh para guru pendidikan dasar di Jepang. Keberhasilan Jepang dalam me- 
ngembangkan Lesson Study mulai diikuti oleh beberapa negara lain, termasuk di Amerika Serikat yang secara gigih dikembangkan dan dipopulerkan oleh Catherine Lewis. Sementara di Indonesia pun saat ini mulai gencar disosialisasikan untuk dijadikan sebagai sebuah model dalam rangka meningkatkan proses pembelajaran siswa, bahkan pada beberapa sekolah sudah mulai dipraktekkan. Meski pada awalnya, Lesson Study dikembangkan pada pendidikan dasar, namun saat ini ada kecenderungan untuk diterapkan pula pada pendidikan menengah dan bahkan pendidikan tinggi.

Lesson Study bukanlah metode dalam pembelajaran, tetapi merupakan salah satu upaya pembinaan untuk meningkatkan proses pembelajaran yang dilakukan oleh sekelompok guru secara kolaboratif dan berkesinambungan, dalam merencanakan, melaksanakan, mengobservasi dan melaporkan hasil pembelajaran. Lesson Study merupakan kegiatan terus menerus yang tiada henti dan suatu upaya untuk mengaplikasikan prinsip-prinsip dalam Total Quality Management, yakni memperbaiki proses dan hasil pembelajaran siswa secara terus-menerus, berdasarkan data. Lesson Study merupakan kegiatan yang dapat mendorong terbentuknya sebuah komunitas belajar (learning society) yang secara konsisten dan sistematis melakukan perbaikan diri. Slamet Mulyana (2007) memberikan rumusan tentang Lesson Study sebagai salah satu model pembinaan profesi pendidik melalui pengkajian pembelajaran secara kolaboratif dan berkelanjutan berlandaskan pada prinsip-psrinsip kolegalitas dan mutual learning untuk membangun komunitas belajar

Bill Cerbin \& Bryan Kopp mengemukakan bahwa Lesson Study memiliki 4 (empat) tujuan utama, yaitu untuk: (1) memperoleh pemahaman yang lebih baik tentang bagaimana siswa belajar dan guru mengajar; (2) memperoleh hasil-hasil tertentu yang dapat dimanfaatkan oleh para guru lainnya, di luar peserta Lesson Study; (3) meningkatkan pembelajaran secara sistematis melalui inkuiri kolaboratif. (4) membangun sebuah pengetahuan pedagogis, dimana seorang guru dapat menimba pengetahuan dari guru lainnya

Lesson study diperkenalkan di Indonesia melalui kegiatan piloting yang dilaksanakan dalam proyek foloow-up IMSTEP(Indonesia Mathematics \& Science Teacher Education Project)-JICA sejak tahun 2001 di tiga perguruan tinggi UPI Bandung, UNY Yogyakarta dan UM Malang. Di UM Malang, lesson study dikenalkan secara formal oleh JICA sepert Eisoke Saito pada Januari 2004. Hasil uji coba penerapan lesson study bagi sekolah laborat di Malang tahun 2004 menunjukkan terjadinya peningkatan profesionalisme guru dalam melakukan pembelajaran di sekolah, meningkatkan kolaborasi akademik dan dapat dilakukan secara berkelanjutan.

Lesson study telah diujicobakan di sekolah lab SMA Permata Mansamat di kepulauan Banggai Sulawesi Tengah (Asep Sapaat,2009). Dua kali sebulan, para guru dimina tampil dalam micro teaching sebelum dilaksanakan di depan kelas. Di awal pendampingan, guru disadarkan pada arti pentingnya perubahan diri guna mengikuti perkembangan di dunia pendidikan, membekali guru agar mampu melaksanakan pembelajaran yang aktif inovatif kreatif dan efektif, mengenali masalah dan mencari pemecahan, membudayakan gemar membaca dan menulis, dan memberikan pemahaman yang utuh tentang komputer dan internet. Dari kegiatan lesson study banyak hal penting yang diperoleh dan berdampak positif bagi semua guru demi meningkatkan kualitas proses dan hasil belajar

Di wilayah Bandung, lesson study berawal dari tindak lanjut workshop guruguru SMP. Pada kegiatan pertama dilak- 
sanakan awal tahun 2005 di empat lokasi (SMPN 24, SMPN 38, SMPN 43 dan SMP Sebelas Maret). Kegiatan serupa melibatkan guru SMP Negeri percontohan UPI (SMP Lab) tanggal 12 dan 23 Maret 2006. Dari penuturan tersebut belum dijelaskan secara eksplisit dampak dari kegiatan, baik kepada guru maupun kepada siswanya. Namun dengan telah berjalannya dengan baik dapat di indikasikan bahwa kegiatan lesson study di wilayah Bandung bisa diterima oleh guru model, guru mitra bahkan guru-guru yang terikat dalam MGMP.

Di Surabaya, lesson study dimulai sejak tahun ajaran 2008/2009 kepada guruguru MIPA SMP Negeri se Kota Surabaya dengan pendampingan dari UNESA. Selama tiga tahun akan melibatkan 70 guru yang berasal dari 30 SMP Negeri. Tanggal 24 Juli 2008 telah dilakukan pelatihan kepada Kepala Sekolah dan Pengawas. Tanggal 2526 Juli 2008 pelatihan guru fasilitator, sedang tanggal 4 Agustus 2008 pertemuan pertama pesereta lesson study di base camp dari empat wilayah (utara, selatan, timur dan barat). Kegiatan berikutnya setiap hari Sabtu, dan kegiatan open lesson terakhr tanggal 1 Nopember 2008. Sekalipun belum ada publikasi laporan tentang pelaksanaan lesson study dimaksud, namun dapat diduga bahwa pelaksanaan lesson study dibawah pendampingan UNESA napaknya tidak ada hambatan

\section{Tujuan dan Manfaat}

\section{a. Tujuan}

Secara umum, tujuan kegiatan ini ditujukan untuk membekali guruguru SD N Gentan Baki Sukoharjo tentang inovasi pendidikan berdasar pendekatan Lesson Study agar dapat diterapkan / diujicobakan di sekolahsekolah, paling tidak sebagai variasi metode pembelajaran yang selama ini dilaksanakan secara konvensional. Lebih rincinya, tujuan kegiatan ini adalah:
1) Sosialisali tentang inovasi pendidikan matematika berdasar pendekatan Lesson Study

2) Melatih guru-guru SD N Gentan

Baki Sukoharjo secara simulatif tentang pelaksanaan Lesson Study di sekolah

3) Membangkitkan motivasi guru agar tertarik untuk mengikuti program pelatihan (workshop) secara lebih komprehensif

Kedepan, agar guru-guru bisa melaksanakan Lesson Study di sekolah untuk dapat meningkatkan pemahaman konsep siswa yang ujung-ujungnya adalah meningkatnya prestasi belajar siswa.

\section{b. Manfaat}

\section{1) Manfaat Teoritis}

Kegiatan ini memberikan sumbangan kepada pembelajaran matematika. Utamanya pada layanan belajar. Telah diakui secara luas bahwa layanan belajar memiliki peran yang cukup besar bagi siswa dalam hal motivasi, penampilan dan kecakapannya dalam bidang study Oleh karenanya wajar bila guru mempunyai keyakinan intervensi terhadap siswanya melalui inovasi pembelajaran.

Secara khusus kegiatan ini memberikan kontribusi kepada strategi pembelajaran berupa pergeseran paradigma dari paradigma guru mengajar kepada siswa belajar, dari paradigma suasana takut menjadi senang belajar matematika dalam suasana gembira di kelas, dan yang penting adanya perubahan paradigna guru sebagai validator menjadi sebagai fasilitator, dan ini merupakan aspek esensial dalam pembelajaran berdasar KTSP 


\section{Manfaat Praktis}

Pada dataran praktis, kegiatan ini memberikan sumbangan kepada lembaga pendidikan formal LPTK dan kepada guru di sekolah. Lembaga pendidikan formal LPTK dapat memanfaatkan hasil kegiatan ini untuk mengembangkan kompetensi calon guru di bidang materi pelajaran mengingat kompetensi ini merupakan kebutuhan yang mendesak dengan telah diberlakukannya KBK pada tahun 2004 yang akhirnya disempurnakan menjadi KTSP. Bagi guru, model produk kegiatan ini dapat digunakan untuk menyelenggarakan layanan pembelajaran yang inovatif, diaplikasikan dan dapat pula dipakai untuk mengembangkan model-model pembelajaran yang lainnya.

\section{METODE KEGIATAN}

\section{Desain kegiatan tertuang dalam tiga tahapan yaitu:}

a. Tahap pertama (I): sosialisasi dan simulasi Lesson Study berupa Ceramah dan diskusi tentang Pendidikan Matematika Realistik (PMR) dan Lesson Study (LS) dan Peragaan pelaksanaan Lesson Study di kelas sebagai simulasi.

b. Tahap kedua (II): lokakarya/pelatihan penyusunan program, persiapan pelaksanaan Lesson Study .

c. Tahap ketiga (III): pelaksanaan Lesson Study di sekolah, beserta sistem monitoringnya.

\section{Pelaksanaan kegiatan tahap pertama}

(I)

a. Persiapan: (1) Tim melakukan koordinasi dengan Kepala Sekolah, (2) Setelah disepakati kedua belah fihak, Kepala Sekolah mengkoordinasi calon peserta dan menyiapkan ako- modasi/tempat. Sedang tim menyiapkan materi/makalah beserta media pembelajarannya (transparansi, LCD, alat peraga, dll), (3) Menetapkan kelompok sasaran, (4) Menentukan pelaksanaan hari $\mathrm{H}$

\section{b. Pelaksanaan kegiatan:}

1. Tempat dan waktu. Kegiatan dilaksanakan tgl.13 Januari 2010 dengan mengambil tempat di SDN Gentan I Baki Sukoharjo

2. Peserta sosialisasi: Banyaknya peserta 26 orang terdiri dari Guru SDN I sebanyak 11 orang, dan Guru SDN II: 9 orang

3. Pokok-pokok kegiatan :

a) Pengantar Kepala Sekolah: Endah Setyati, S.Pd. Disampaikan latar belakang kegiatan sebagai salah satu kerjasama dengan FKIP-UMS.

b) Pengantar Ketua pelaksana: Drs. Slamet Hw, M.Pd. Disampaikan pentingnya kegiatan sebagai salah satu realisasi Tri Dharma Perguruan Tinggi. Ada tiga tahapan yang direncanakan: (1) Pengenalan / sosialisasi LS, (2) Pembimbingan pelaksanaan LS di kelas, dan (3) Monitoring LS mandiri.

c) Ceramah dan Diskusi LS oleh Dr. Tjipto Subadi (Makalah1). Mengenalkan Perubahan Paradigma baru dalam Pembelajaran inovatif, diteruskan tanya jawab/diskusi. Ceramah dan diskusi LS oleh Dr. Sutama (Makalah-2). RME dan CTL memiliki dasar filosofis yang sama, hanya saja RME khusus untuk matematika dan CTL untuk semua 
mata pelajaran. Belajar akan bermakna bagi siswa bila informasi yang baru bisa dikaitkan/dikonstruksi dengan pengetahuan yang telah dimiliki sebelumnya. Oleh karenanya, dengan teori konstruktivisme maka siswa sendiri yang harus "aktif" mengkonstruksi pengetahuan sehingga belajarnya menjadi bermakna. Jadi pembelajaran yang lebih mengutamakan keaktifan siswa itulah salah satu paradigma pembelajaran yang inovatif.

\section{Pelaksanaan kegiatan tahap kedua (II)}

Tindak lanjut dari sosialisasi PMR dan LS dilakukan pembimbingan untuk menyusun rencana program pembelajaran (RPP). Bimbingan berjalan sebanyak 5 (lima) kali kepada 6 (enam) calon pelaksana LS. Bimbingan lebih ditujukan kepada kemampuan guru: (1) mengembangkan SK dan KD kedalam indikatorindikator, (2) merumuskan tujan pembelajaran, (3) mengembangkan materi ajar, (4) pemilihan metode dan strategi pembelajaran, (5) pemilihan media dan sumber belajar, (6) mengembankan evaluasi pembelajaran.

\section{HASIL DAN PEMBAHASAN}

Berdasar pengamatan selama berlangsungnya sosialisasi dan juga memperhatikan tanggapan serta masukan tertulis dari peserta, dapat dilaporkan sebagai berikut:

1. Guru-guru sangat antusias dan aktif selama mengikuti pembekalan LS.

2. Guru-guru ingin mengetahui lebih mendalam tentang LS. Selesai pelaksanaan simulasi sederhana tentang LS dilanjutkan dengan penjelasan singkat dasar teori yang melatar belakangi, dan ternyata pada umumnya peserta ingin mengetahui lebih banyak lagi tentang LS.

3. Sangat menginginkan tindak lanjut. Terkait point-2 diatas, kebanyakan peserta menginginkan adanya tindak lanjut seperti pelatihan-pelatihan agar guru bisa melaksanakan di kelas.

4. Sebagian besar guru berkeyakinan: dengan LS akan membantu meningkatkan pemahaman siswa tentang matematika yang ujung-ujungnya diharapkan akan dapat meningkatkan prestasi belajar

5. Setelah sosialisasi, kepada calon pelaksana LS akan diberi bimbingan atau pendampingan tentang penyusunan rencana pelaksanaan LS melalui penyusunan RPP

6. Lebih lanjut hasil dari kegiatan ini adalah: Meningkatnya kompetensi profesional guru, yaitu penguasaan dan pengembangan materi pembelajaran secara luas dan mendalam yang meliputi: (1) penguasaan konsep, struktur, dan metode keilmuan yang koheren dengan materi ajar, (2) materi ajar yang ada dalam kurikulum sekolah, (3) hubungan konsep antar mata pelajaran terkait, (4) penerapan konsepkonsep keilmuan dalam kehidupan

7. Meningkatnya kompetensi pedagogik, yaitu kemampuan dalam pengelolaan peserta didik yang meliputi: (1) pemahaman wawasan atau landasan kependidikan; (2) pemahaman terhadap peserta didik; (3) pengembangan kurikulum/ silabus; (4) perancangan pembelajaran; (5) pelaksanaan pembelajaran yang mendidik dan dialogis; (6) evaluasi hasil belajar; dan (7) pengembangan peserta didik untuk mengaktualisasikan berbagai potensi yang dimilikinya

\section{SIMPULAN}

Dari lima tahap rencana kegiatan pengabdian pada masyarakat secara berkesinambungan demi meningkatkan kualitas pem- 
belajaran matematika di sekolah-sekolah, ternyata pelaksanaan tahap pertama dankedua ini dapat dibilang berhasil. Atas dasar itu perlu segera ditindak lanjuti dengan kegiatan berikutnya mengingat guru-guru telah termotivasi untuk mengetahui lebih jauh tentang LS yang untuk selanjutnya akan melaksanakannya di kelas.

Perlu disadari bahwa demi pelaksanaan LS di kelas memang membutuhkan komitmen yang tinggi dari semua fihak yang terkait. Pada awalnya memang membutuhkan biaya yang relatif tidak sedikit utamanya untuk perbanyakan makalah, buku panduan, lembar kerja siswa (LKS), peraga matematika selain untuk pelatihan dan monitoring. Namun demikian dengan kerjasama yang baik antara LPM-UMS, Tim Pengembang Pembelajaran, dan Guru sebagai ujung tombak, insya Allah semua rencana yang baik ini dapat berjalan lancar.

\section{DAFTAR PUSTAKA}

Akhmad Sudrajat. 2009. "Lesson Study untuk Meningkatkan Proses dan Hasil Pembelajaran”. Online: tgl 20 Januari 2009

Armanto, Dian. 2003. Pengembangan Model Pembelajaran Matemaika Berbasis Kompetensi dan Berkonteks Lokal Bagi Guru dan Siswa SD/MI Sumatera Utara. Universitas Negeri Medan

Bill Cerbin \& Bryan Kopp. A Brief Introduction to College Lesson Study. Lesson Study project. online: http://www.uwlax.edu/sotl/lsp/index2.htm

Catherine Lewis. 2004. Does Lesson Study Have a Future in the United States?. Online: http://www.sowi-online.de/journal/2004-1/lesson_lewis.htm

Fauzan, Ahmad 2002. Applying realistic mathematics education in teaching geometry in Indonesian primary schools. Doctoral dissertation, University of Twente, Enschede, The Netherlands.

Goffree, F. 1993. HF: Working on mathematics education. Educational Studies in Nederlands: Freudenthal Institute.

Hadi, Sutarto. 2004. Pengembangan Materi Pemelajaran Matematika Realistik untuk Mendukung Penerapan Kurikulum Berbasis Kompetensi Universitas Lambung Mangkurat Banjarmasin.

Hadi, Sutarto. 2003. 2006. Paradigma Baru Pendidikan Matematika. Makalah Forum Komunikasi Sekolah Inovasi Kalimantan Selatan, 2003; Workshop Lokal PMRI 15-17 Juni 2006 di Yogyakarta.

__ Lesson study Suatu Model untuk meninkatkan Kualitas Pembelajaran di Sekolah. Online: file:///C:/Documents and Settings/AKU/My Documents/ROEBY - LESSON STUDY. online tgl 20 januari 2009

—. Standar Kompetensi Guru. Online tgl 20 Januari 2009

WARTA, Vol .13, No.1, Maret 2010: 55 - 64 
Lesson Study Research Group online: http://www.tc.edu/lessonstudy/whatislessonstudy.html

Marpaung. 2006. "Pendekatan Psikologis dan Budaya untuk Meningkatkan Kualitas Pendidikan Matematika”. Makalah Workshop Lokal PMRI. 15-17 Juni 2006. Yogyakarta

Puskur. 2006. Kurikulum Tingkat Satuan Pendidikan Mata Pelajaran Matematika Sekolah Dasar dan Madrasah Ibtidaiyah. Balitbang. Depdiknas

Slamet Hw. 2009. Simulasi PMRI bagi guru SDN Gentan 17 Februari 2009. Surakarta

Slamet Mulyana. 2007. “Lesson Study.” Makalah. Kuningan: LPMP-Jawa Barat

Wikipedia.2007. Lesson Study. Online: http://en.wikipedia.org/wiki/Lesson_study

Zulkardi. 2002. "Developing a learning environment on Realistic Mathematics Education for Indonesian student teachers". Doctoral dissertation. University of Twente, Enschede, The Netherlands (copy ringkasan) 